\title{
Experiential avoidance versus Decentering abilities: The role of different emotional processes on disordered eating
}

\begin{abstract}
Short title: The role of experiential avoidance and decentering in eating psychopathology
\end{abstract}

\author{
Ana Laura Mendes, MSc \\ Cláudia Ferreira, PhD \\ Joana Marta-Simões, MSc
}

CINEICC

University of Coimbra, Portugal

Correspondence concerning this article should be addressed to:

Ana Laura Mendes, University of Coimbra- Faculty of Psychology and Educational Sciences, Rua do Colégio Novo, Apartado 6153, 3001-802. Coimbra (Portugal)

E-mail: analauramendes@live.com.pt

Phone: (+351)239851450; (+351)203851462 


\section{ABSTRACT}

In modern Western societies, the female body is a predominantly used dimension in self and social evaluations. In fact, the perceived discrepancy between one's current and ideal body image may act as a pathogenic phenomenon for women's well-being. Furthermore, significant differences in the tendency to engage in disordered eating attitudes and behaviours have been verified between women sharing similar characteristics and perceptions about weight and body shape, which suggests that different emotion regulation processes may be involved in this association.

This study thus aims to clarify the mediational effect of two different emotional regulation processes, experiential avoidance and decentering, on the association of weight and body shape variables and shame with disordered eating, in a sample of 760 women.

The tested path model explained $44 \%$ of disordered eating attitudes and behaviours and showed an excellent model fit. Results demonstrated that Body Mass Index had a direct effect, albeit weak, on disordered eating behaviours and that body image discrepancy and shame presented indirect effects through the mechanisms of experiential avoidance and decentering.

Results also revealed that experiential avoidance and decentering showed significant mediator effects on the relationship of weight and body shape and shame with disordered eating behaviors. These findings suggested that while experiential avoidance exacerbates the impact of weight and body shape and shame on disordered eating attitudes and behaviors, decentering seems to attenuate this association.

Our findings appear to offer significant clinical and research implications, highlighting the importance of targeting maladaptive emotion processes through the development of decentering abilities. 
KEYWORDS: Body image, External shame, Decentering, Experiential avoidance, Eating psychopathology

\section{INTRODUCTION}

Women's perceived discrepancies between current and idealized body image has been pointed out as a central risk factor for eating psychopahology [e.g., 1].In fact, several accounts suggested that these perceived discrepancy may explain body image dissatisfaction and promote maladaptive eating-related behaviours [e.g., 2; 3]. Moreover, the perception of one's own body as different from the socially idealized body is associated with negative affect, such as shame [e.g., 4, 5].

In accordance with the biopsychosocial model, shame is a self-conscious emotion which emerges in the relational context when an individual perceives that the self exists negatively in the mind of others (as inferior, undesirable, or powerless [e.g., 6, 7]). Indeed, this painful affect arises as a warning sign that allows to notice one's characteristics and/or behaviours as incapable of positively impressing others, putting the self at risk of criticism and rejection [e.g., 7, 8]. In this sense, shame is fundamentally a socially-focused emotion of great evolutionary significance linked to a series of defense responses (e.g., concealment or submission; [e.g., 8]). Particularly, literature has suggested that some individuals, when dealing with shame experiences, may endorse maladaptive defensive strategies with the purpose of correcting or concealing one's negatively perceived attributes or characteristics [e.g., 9, 10]. In fact, although shame has been highlighted as an adaptive emotion, high levels of shame are strongly associated with several social difficulties, and to different mental health conditions [e.g., 8, 11]. Furthermore, literature suggested shame as a central feature in body image and eating difficulties [e.g., 12, 13]. 
In modern societies the female body shape is a particularly used dimension in self and social evaluations [e.g., 14, 15]. This context may explain shame feelings in women who perceived their body as significantly different from female attractiveness' sociocultural standards. Moreover, negative feelings (e.g., inferiority) may explain women's engagement in maladaptive behaviours [e.g., 16, 17]. In this line, disordered eating behaviours may arise with the intention of controlling weight and body shape and to serve the functional purpose of avoiding being rejected or judged due to one's body image $[12,13]$. However, differences in eating psychopathology between women that shared similar weight and shape perceptions have been reported, which suggests that different emotional regulation processes may be involved in this association.

In accordance with Hayes, Strosahl and Wilson (1999; [18]), human suffering mainly emerges from attempts to avoid or control adverse inner events (e.g., emotions, sensations and thoughts; [19]). For that reason, ACT's interventions aim to increase psychological flexibility by developing one's availability to experience and accept internal experiences [20].

Experiential avoidance is a main process of psychological inflexibility conceptualized as the unwillingness to be in contact with certain particular inner experiences (e.g., emotions, thoughts or bodily sensations) and the effort to avoid or control the frequency, form and context in which they occur [e.g., 18, 21]. This process is not by itself malignant, since its evolutionary adaptive function, however, it can associate with several psychopathological processes (e.g., rumination, maladaptive perfectionism and cognitive suppression; [e.g., 22, 23, 24]) and become a disordered process, by serving the purpose of inflexibly and rigidly controlling unwanted internal events [25]. Research has shed light on the role of different psychological inflexibility processes in the proneness of some individuals to eating disorders [e.g., 26], namely 
experiential avoidance, manifested by extreme diet, binge eating or compensatory behaviours [27, 28].

In contrast, and in line with the promotion of psychological flexibility, decentering is as an important mechanism against psychopathological symptomatology and a fundamental therapeutic process of change [e.g., 18, 29]. In fact, this process is conceptualized as the capability of observing and coping with one's inner experiences (thoughts or feelings) as subjective and temporary events which occur in the mind, as opposed to objective reflections of the self or reality $[30,31]$. Decentering abilities, contrarily to self-focused forms of attention, allow individuals to observe one's feelings and thoughts and to recognize them as mere products of the mind that do not demand particular responses [30]. Furthermore, decentering has been described as the ability to adopt a present-focused, nonjudging and accepting attitude towards one's own private events [32]. Research has pointed out the positive association between the adoption of a decentered perspective and well-being [30; 33].

The present study examines a path model which explores the role of experiential avoidance and decentering in the relationship between core risk factors of eating psychopathology and the engagement in maladaptive eating behaviours. Specifically, this model explored the mediational role of these different emotional processes in the link between body mass index (BMI), body image discrepancy and external shame and disordered eating behaviours. It is hypothesized that experiential avoidance may fuel the association between body image variables and external shame and eating psychopathology's variance. In turn, it is expected that decentering abilities attenuate these association.

\section{MATERIALS AND METHODS}


The current investigation is part of a wider research project about the impact of emotion regulation processes in quality of life and eating psychopathology, in the Portuguese population.

Present study respected the ethical and deontological issues inherent to scientific research. Self-report measures were administered by the authors after the Ethic Committees and boards of the institutions involved (e.g., colleges, private companies and retail services) approved the research. All participants gave their written informed consent after being informed about the purpose and procedures of the study, the voluntary nature of their cooperation and the confidentiality of the data.

The original sample consisted of 1099 participants of both genders, aged between 17 to 60 years. However, taking into account the aims of this study, data were cleaned in order to exclude (1) male participants, (2) participants who were younger than 18 or older than 35 years, and (3) protocols in which more than $15 \%$ of the responses were missing. The final sample was composed of 760 women.

\section{PARTICIPANTS}

A total of 760 women from the general population (including students and individual working in private companies and retail services), with ages ranging from 18 to 35 , participated in this study. Participants presented a mean age of $20.66(S D=2.18)$ and a mean of $13.23(S D=1.61)$ years of education.

Participant’s Body Mass Index (BMI) mean was $21.86(S D=3.13)$, corresponding to normal weight values [34]. Moreover, it was verified that the sample's BMI distribution is equivalent to the female Portuguese population's BMI distribution [35]. 


\section{MEASURES}

Body Mass Index (BMI); BMI, a measure of body fat, was calculated from participant's self-reported current height and weight using the Quetelet Index $\left(\mathrm{Kg} / \mathrm{m}^{2}\right)$.

Figure Rating Scale (FRS; [36, 37]); FRS is a well-known measure of body image with good psychometric properties [36]. It consists of a series of nine_schematic figures of different sizes, ranging from a very thin silhouette (1) to a very large silhouette (9). Participants were asked to select two silhouettes, one that best indicate their selfperceived current body shape and other that represent their ideal body image. FRS was, therefore, used as a measure of the discrepancy between the actual and the ideal body image, by calculating the difference between these two silhouettes.

Other As Shamer Scale-2 (OAS-2; [38]). This is a shorter version of the OAS [39] consisting 8 items, to evaluate external shame, that is, the perception that others judge the self negatively (e.g., "I think that other people look down on me"). The response options are rated on a five-point scale, ranging from 0 ("never) to 4 ("almost always"). Higher results in this scale indicate higher levels of external shame [39]. OAS-2 has shown excellent internal consistency (0.82); concerning the current study, the Cronbach's alpha was 0.92 .

Experiences Questionnaire (EQ; [30, 40]). The EQ comprises 20 items that aim to assess the participant's ability for decentration and desidentification with negative thoughts in daily experiences (e.g., "I can observe unpleasant feelings without being drawn into them"). These items are scored on a 5-point scale (ranging from 1: Never to 5: Always), according to their frequency, with higher scores indicate greater capability to view one's feelings and thoughts as temporary and separated from the self. This scale has shown good reliabilities in the original version $(\alpha=0.83)$ and in the Portuguese version $(\alpha=0.81)$. In this study its Cronbach's alpha was 0.79 . 
Acceptance and Action Questionnaire-II (AAQ-II; [41, 42]). The AAQ-II is a 7 item scale which assesses experiential avoidance (e.g., 'I worry about not being able to control my worries and feelings'). Participants evaluates each item on a 7-point scale (ranging from 0: Never true, to 7: Always true) according to their accuracy. This measure revealed good internal consistency values in the original study ( $\alpha=.84$, across six samples) and in the Portuguese validation study $(\alpha=0.90)$. In the present study the Cronbach's alpha was 0.90 .

Eating Disorder Examination Questionnaire (EDE-Q; [43, 44]); The EDE-Q is a 36 item self-report questionnaire adapted from the Eating Disorder Examination Interview (EDE; [45]). It consists of four subscales (restraint, weight concern, shape concern and eating concern) which evaluate the frequency and intensity of disordered eating attitudes and behaviours. The items are rated for frequency of occurrence or for the severity. Higher scores reveal greater levels of disturbance. This measure presented good psychometric properties in both the original and the Portuguese versions. In the current study the global and subscale's score of EDE-Q presented a Cronbach's alpha ranging from 0.74 to 0.93 .

\section{DATA ANALYSIS}

Statistical analyses were conducted using the software IBM SPSS Statistics 22.0 (v.22; SPSS Inc., Chicago, IL), and path analysis was performed via the software AMOS [46].

Descriptive statistics were performed (means and standard deviations), in order to analyze the characteristics of the final sample. Product-moment Pearson correlation analyses were performed [47] to examine the relationships between the study's variables. Finally, path analyses were conducted to explore whether BMI, body-image discrepancy 
(FRS) and external shame (OAS-2) would predict disordered eating attitudes and behaviours (global score of the EDE-Q), mediated by decentering (EQ) and experiential avoidance (AAQ-II). BMI, body-image discrepancy and external shame were considered as exogenous variables; decentering and experiential avoidance were hypothesized as mediator variables, and EDE-Q was the dependent endogenous variable. The MaximumLikehood method was used to estimate the significance of all model path coefficients and fit statistics, and a series of goodness-of-fit measures were calculated in order to examine the adequacy of the overall model (e.g., CMIN/DF; CFI; TLI; RMSEA; [48]). The adjustment of the path model to the empirical data was analysed recurring to the chisquare goodness-of-fit (that indicates a good fit when non-significant; [49]), the Comparative Fit Index (CFI) and the Tucker and Lewis Index (TLI) which reveal a good model fit when values are superior to $.95(48,50)$, and the Root Mean Squared Error of Approximation (RMSEA; which reveals a good adjustment when values are inferior to .06; [48]). Resorting to the Bootstrap resampling method, the significance of the direct, indirect and total effects was also examined, with 5000 Bootstrap samples, and 95\% biascorrected confidence intervals (CI) around the standardized estimates of total, direct and indirect effects. The fit of individual parameters in the model was assessed through the analysis of parameters estimates $(b$; that indicate the model is poor when their signal fall outside the admissible range signal; [51]) and standard errors (SE; another indicator of poor model fit when excessively large or small; [51]). The indirect effects were considered statistically different from zero $(p<0.05)$ if zero was not on the interval between the lower and the upper bound of the $95 \%$ bias-corrected confidence interval [52]. 


\section{RESULTS}

\section{PRELIMINARY ANALYSES}

Uni and multivariate normality was confirmed by the analysis of Skewness (Sk) and Kurtosis $(\mathrm{Ku})$ values [52]. In addition, preliminary analyses showed that data followed the assumptions of normality, homoscedasticity, linearity, independence of errors and multicollinearity among the variables [53].

\section{DESCRIPTIVE AND CORRELATIONS ANALYSES}

Descriptive and Pearson's correlation results are present in Table 1.

Table 1

Means (M), Standard Deviations (SD), and Intercorrelation scores on self-report measures $(n=760)$.

\begin{tabular}{|c|c|c|c|c|c|c|c|c|c|c|c|}
\hline Measures & $M$ & $S D$ & 1 & 2 & 3 & 4 & 5 & 6 & 7 & 8 & 9 \\
\hline 1.BMI & 21.86 & 3.13 & 1 & - & - & - & - & - & & & \\
\hline 2.BID & .66 & .98 & $.58 * * *$ & 1 & - & - & - & - & & & \\
\hline 3.OAS-2 & 5.75 & 5.11 & .04 & $.13 * * *$ & 1 & - & - & - & & & \\
\hline 4.EQ & 34.18 & 5.11 & -.01 & $-.12 * * *$ & $-.39 * * *$ & 1 & - & - & & & \\
\hline 5.AAQ-II & 34.27 & 7.78 & -.04 & .07 & $.53 * * *$ & $-.51 * * *$ & 1 & - & & & \\
\hline 6.EDE-Q_total & 1.32 & 1.09 & $.34 * * *$ & $.54 * * *$ & $.34 * * *$ & $-.34 * * *$ & $.38^{* * *}$ & 1 & & & \\
\hline 7.EDE-Q_rest & .90 & 1.09 & $.24 * * *$ & $.41 * * *$ & 16 . $* * *$ & $-.14 * * *$ & $.17 * * *$ & $.74 * * *$ & 1 & - & - \\
\hline 8.EDE-Q_wei.com & 1.69 & 1.36 & $.39 * * *$ & $.51 * * *$ & $.31 * * *$ & $-.32 * * *$ & $.34 * * *$ & $.93 * * *$ & $.57 * * *$ & 1 & - \\
\hline 9.EDE-Q_sha.com & 1.79 & 1.45 & $.31 * * *$ & $.51 * * *$ & $.36^{* * * *}$ & $-.36 * * *$ & $.41^{* * * *}$ & $.96^{* * * *}$ & $.59 * * *$ & $.89 * * *$ & 1 \\
\hline 10.EDE-Q_eat.com & .60 & .86 & $.23 * * *$ & $.40 * * *$ & $.32 * * *$ & $-.33 * * *$ & $.37 * * *$ & $.89 * * *$ & $.58 * * *$ & $.69 * * *$ & $.74 * * *$ \\
\hline
\end{tabular}

Note $:$ BMI = Body Mass Index; BID = Body Image Discrepancy; OAS-2 = Other As Shamer; EQ

= Experiences Questionnaire; AAQ-II = Acceptance and Action Questionnaire-II; EDE-Q_total $=$ Eating Disorder Examination Questionnaire (global score); EDE-Q_rest = Restraint subscale of EDE-Q; EDE-Q_wei.com = Weight Concern subscale of EDE-Q; EDE-Q_sha.com = Shape Concern subscale of EDE-Q; EDE-Q_eat.com = Eating Concern subscale of EDE-Q. 
$* * * p<.001$

Results showed that BMI was positively and strongly associated with body image discrepancy (BID) and moderately with eating psychopathology (EDE-Q). Also, results demonstrated that BMI revealed a non-significant association with external shame (OAS2), decentering abilities (EQ) and experiential avoidance (AAQ-II). Furthermore, results indicated that BID presented weak correlations with OAS-2 and EQ, positive and negative respectively and non-significant association with AAQ-II. Also, BID showed positive and strong correlation with EDE-Q.

OAS-2 presented significant associations with the studied emotional processes, a negative and moderate correlation with EQ and a positive and strong associations with AAQ-II. Further, OAS-2 showed a positive and moderate association with the global measure of eating psychopathology (EDE-Q). EQ and AAQ-II revealed a negative and strong association between each other and were moderately associated with EDE-Q (with negative and positive correlations, respectively). Finally, regarding the EDE-Q's subscales, positive associations, from weak to moderate magnitudes, were found with BMI. With BDI, OAS-2 and AAQ, the EDE-Q's subscales correlated positively, with moderate to high correlations (except for the weak correlation between EDE-Q_rest with OAS). Additionally, negative correlations were found between EDE-Q's subscales and EQ.

\section{PATH ANALYSIS}

Path analysis was performed to test whether decentering and experiential avoidance mediate the effect of BMI, body image discrepancy and external shame on the engagement in disordered eating behaviours. 
The theoretical model was tested by a saturated model (i.e., with zero degrees of freedom), comprising 24 parameters. Results indicated that three paths were not significant: the direct effect of body image discrepancy on experiential avoidance $\left(b_{\mathrm{BD}}=\right.$ $\left..425 ; S E_{\mathrm{b}}=.325 ; Z=1.31 ; p=.191\right)$; the direct effect of $\mathrm{BMI}$ on decentering $\left(b_{\mathrm{BMI}}=.089\right.$; $\left.S E_{\mathrm{b}}=.065 ; Z=1.58 ; p=.169\right)$, and direct effect of BMI on experiential avoidance $\left(b_{\mathrm{BMI}}\right.$ $\left.=-.124 ; S E_{\mathrm{b}}=.078 ; Z=-1.59 ; p=.112\right)$. These paths were progressively removed and the rectified model was then tested.

The final model (Figure 1) presented an excellent model fit, with a non-significant Chi-Square $\left[\mathrm{X}_{(3)}^{2}=6.127 ; p=.106\right]$ and excellent goodness-of-fit indices $(\mathrm{CMIN} / \mathrm{DF}=$ 2.042; CFI $=.998 ; \mathrm{TLI}=.988 ; \mathrm{RMSEA}=.037 ;[\mathrm{IC}=.000-.079 ; p=.631] ;[53]$. All path coefficients were statistically significant $(p<.05)$ and in the expected directions. The model explained $44 \%$ of EDE-Q and accounted for $16 \%$ and $28 \%$ of decentering and experiential avoidance, respectively.

Body image discrepancy predicted decentering and EDE-Q variance, with a direct effect of $-.07\left(b_{\mathrm{BD}}=-.350 ; S E_{b}=.162 ; Z=-2.168 ; p=.030\right)$ and $.44\left(b_{\mathrm{BD}}=.488 ; S E_{b}=\right.$ $.038 ; Z=12.877 ; p<.001)$, respectively. BMI directly predicted higher levels of EDE$\mathrm{Q}$, with an effect of $.09\left(b_{\mathrm{BMI}}=.033 ; S E_{b}=.012 ; Z=2.810 ; p=.005\right)$. In turn, external shame had a direct effect of -.38 on decentering $\left(b_{\mathrm{OAS}}=-.384 ; S E_{b}=.034 ; Z=-11.454 ; p\right.$ $<.001)$, of .53 on experiential avoidance $\left(b_{\mathrm{OAS}}=.868 ; S E_{b}=.051 ; Z=17.170 ; p<.001\right)$ and of .10 on EDE-Q $\left(b_{\mathrm{OAS}}=.022 ; S E_{b}=.007 ; Z=3.194 ; p<.010\right)$. It was also verified that both decentering and experiential avoidance had a direct effect of -.13 $\left(b_{\mathrm{EQ}}=-.027\right.$; $\left.S E_{b}=.007 ; Z=-3.972 ; p<.001\right)$ and $.24\left(b_{\mathrm{AAQ}}=.031 ; S E_{b}=.005 ; Z=6.772 ; p<.001\right)$ on EDE-Q, respectively.

The analysis of indirect effects revealed that body image discrepancy presented an indirect effect of .01 on EDE-Q through the mechanisms of decentering (95\% CI = 
$.000-.019)$. External shame presented an indirect effect of $.17(95 \% \mathrm{CI}=.14-.22)$ on EDE-Q, which was partially mediated through the mechanisms of decentering and experiential avoidance, respectively.

Overall, the model accounted for $44 \%$ of eating psychopathology's variance, and revealed that decentering abilities and the tendency to engage in experiential avoidance mediate the impact of body image discrepancy and external shame on disordered eating behaviours.

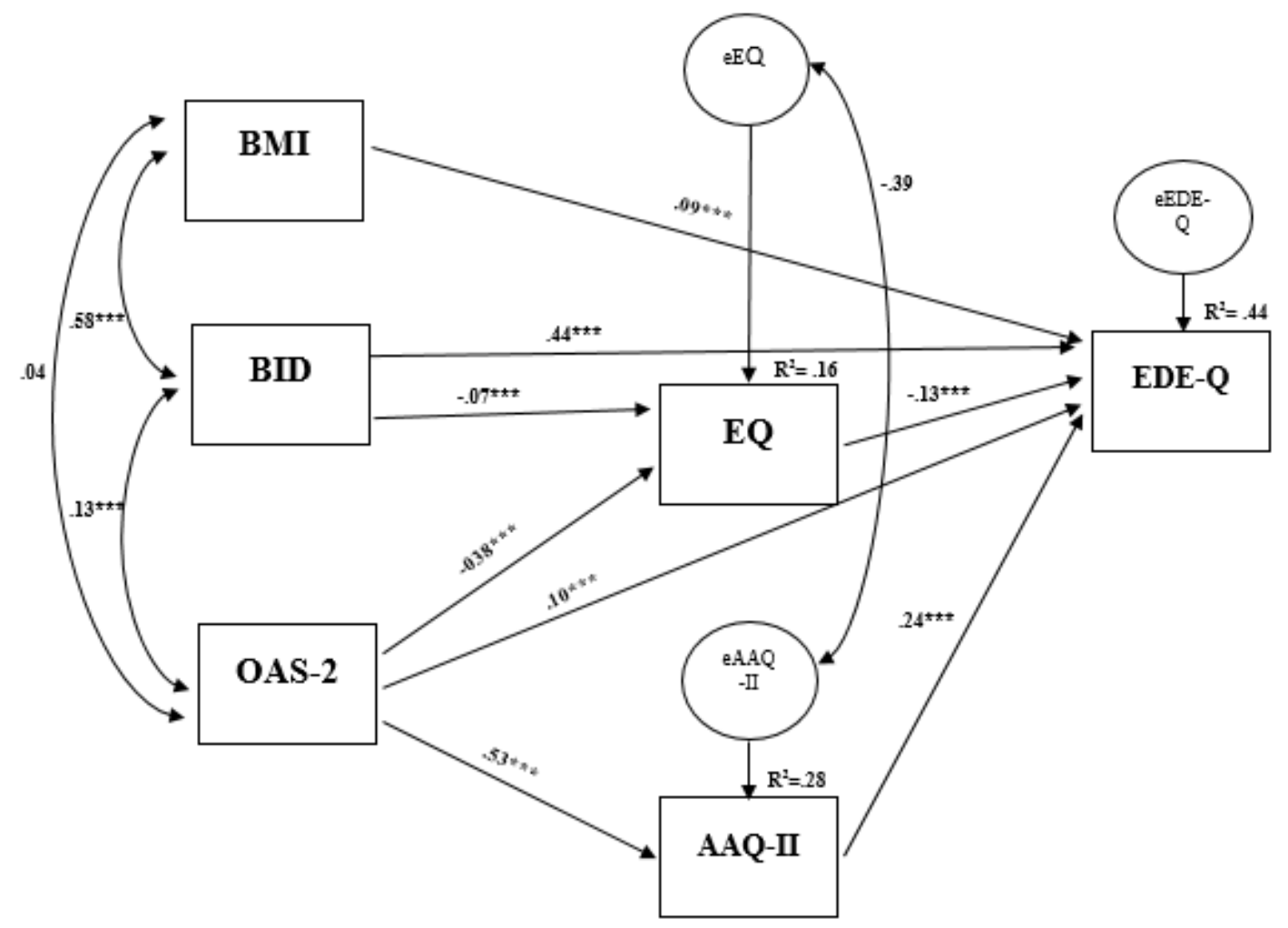

Figure 1. Final path model. Note: Standardized path coefficients among variables are presented. All path coefficients are significant at the 0.5 level; $* * * p<.001$.

\section{DISCUSSION}

Consistent empirical evidence has been suggesting that the perceived discrepancy between one's current weight and body shape and an ideal body image as a pathogenic phenomenon for women's well-being and mental health [e.g., 2]. Several studies have 
suggested that the pervasive effect this discrepancy may be explained by shame feelings and engagement in disordered eating attitudes and behaviours [e.g., 9]. Nevertheless, research has pointed out significant differences in the tendency to adopt disordered eating behaviours between women that shared similar weight and body shape characteristics and perceptions, which suggests that different emotional regulation processes may be involved in this association.

The current study aimed further explore how experiential avoidance and decentering abilities mediate the impact of core risk factors of eating psychopathology (BMI, body image discrepancy and external shame) on the engagement in disordered eating behaviours.

Our results seem to corroborate literature [e.g., 2, 3] and are in accordance with our hypothesis, indicating that BMI, body image discrepancy and external shame are linked to higher levels of disordered eating behaviours. Furthermore, these findings confirm previous research [e.g., 28, 33] revealing the moderate association of decentering abilities and experiential avoidance on EDE-Q (with negative and positive correlations, respectively).

These associations were further examined through a path analysis that tested the impact of BMI, body image discrepancy and external shame on EDE-Q, considering the mediator effect of experiential avoidance and decentering abilities. Results showed that the tested model explained a total of $44 \%$ of eating psychopathology's variance and presented an excellent model fit. Moreover, results indicated that women who presented higher body image discrepancy, defined as the difference between one's perceived current body shape and ideal body image [37], and showed higher levels of shame revealed a greater tendency to engagement in disordered eating attitudes. Also, BMI revealed a significant, albeit weak, direct impact on eating psychopathology. It is also noteworthy 
that the impact of body image discrepancy and external shame on disordered eating behaviours were partially mediated by experiential avoidance and decentering abilities. These findings indicate that even higher discrepancy between one's current and idealized body image and shame directly impact on the adoption of maladaptive eating behaviours, the attempt to control or avoid inner experiences significantly amplifies these associations. In contrast, decentering (that is, the ability to adopt a present-focused, nonjudging and accepting attitude towards one's own thoughts and feelings [32]) seems to attenuate the impact of the negative perception of body image and shame on disordered eating. Our results seem to suggest that decentering abilities and experiential avoidance are important mechanisms to explain the impact of body image negative perceptions and a sense of inferiority or undesirability on the engagement in disordered eating behaviours. In fact, the current study suggests that the impact of body image discrepancy and external shame in the proneness to eating psychopathology is mediated through lower levels of decentering and higher levels of experiential avoidance.

However, the present results should be considered along with several limitations. Firstly, the main limitation in this study concerns its cross-sectional nature, which does not allow the inference of casual directions between the studied variables. In order to determine the directionally of the relations, a longitudinal research should be conducted. Another limitation is the use of a sample exclusively composed of women from the general population. Even though the engagement in disordered eating behaviours is more prevalent in females, upcoming studies should explore this model in male samples and investigate gender differences. Future research should also analyze our hypothesis in clinical populations (e.g., obese and eating disorder patients). Finally, another possible limitation is related to the use of self-report measures, which may be susceptible to biases 
and impair the generalization of the data. Future research should use other non-self-report instruments (such as structured interviews), in order to test our findings.

In conclusion, our results seem to support the hypothesis that the impact of body image discrepancy, and external shame on disordered eating behaviours is carried by the effect of lower levels of decentering abilities and higher levels of experiential avoidance. Furthermore, our findings seem to hold relevant contributions for the development of intervention community programs to target body and eating difficulties, emphasizing the importance of the development of decentering and acceptance abilities.

\section{Compliance with ethical standards}

Ethical approval: All procedures performed in studies involving human participants were in accordance with the ethical standards of the institutional research committee and with the 1964 Helsinki declaration and its later amendments or comparable ethical standards.

Informed consent: Informed consent was obtained from all individual participants included in the study.

Conflict of interest: The authors of this manuscript declare no conflict of interest.

\section{ORCID}

Ana Laura Mendes: orcid.org/0000-0002-9889-5855

Joana Marta-Simões: orcid.org/0000-0002-7807-8575

Cláudia Ferreira: orcid.org/0000-0002-7020-9606 


\section{REFERENCES}

1. Blowers LC, Loxton NJ, Grady-Flesser M, Occhipinti S, Dawe S (2003) The relationship between sociocultural pressure to be thin and body dissatisfaction in preadolescent girls. Eating Behaviours 4(3): 229-244. doi:10.1016/S1471 0153(03)00018-7.

2. Mond J, Mitchison D, Latner J, Hay P, Owen C, Rodgers B (2013) Quality of life impairment associated with body dissatisfaction in a general population sample of women. BMC Public Health 3(13). Doi:10.1186/1471-2458-13-920

3. Stice E, Shaw HE (2002) Role of body dissatisfaction in the onset and maintenance of eating pathology: A synthesis of research findings. Journal of Psychosomatic Research 53(5): 985-993. doi:10.1016/S0022- 3999(02)00488-9.

4. Furnham A, Badmin N, Sneade I (2002) Body Image Dissatisfaction: Gender Differences in Eating Attitudes, Self-Esteem, and Reasons for Exercise. The Journal of Psychology 136(6): 581-596. doi: 10.1080/00223980209604820

5. Gilliard TS, Lackland DT, Mountford WK, Egan BM (2007) Concordance Between Self-Reported Heights and Weights and Current and Ideal Body Images in Young Adult African American Men and Women. Ethnicity Disease 17(4): 617-623.

6. Gilbert P (2007) The evolution of shame as a marker for relationship security: a biopsychosocial approach. In: Tracy J, Robin R, Tangney J (eds) The self-conscious emotions: theory and research. New York, Guilford, pp. 283-309

7. Tangney JP, Dearing RL (2002) Shame and Guilt. New York, Guilford Press.

8. Gilbert P (2002) Body shame: A biopsychosocial conceptualization and overview with treatment implications. In: Gilbert P, Miles J (eds) Body Shame: Conceptualisation, research and treatment. New York, Brunner Routledge, pp.3-54 
9. Ferreira C, Trindade IA, Ornelas L (2015) Exploring drive for thinness as a perfectionistic strategy to escape from shame experiences. The Spanish journal of psychology 18. doi:10.1017/sjp.2015.27.

10. Hewitt PL, Flett GL, Sherry SB, Habke M, Parkin M, Lam RW, McMurtry B, Ediger E, Stein M, Fairlie P (2003) The interpersonal expression of perfectionism: Perfectionistic self-presentation and psychological distress. Journal of Personality and Social Psychology 84(6): 1303-1325. doi: 10.1037/0022- 3514.84.6.1303.

11. Lamont JM (2015) Trait body shame predicts health outcomes in college women: a longitudinal investigation. J Behav Med.doi:10.1007/s10865-015-9659-9

12. Goss KP, Gilbert P (2002) Eating disorders, shame and pride: A cognitivebehavioural functional analysis. In: Gilbert P, Miles J (eds) Body shame: Conceptualization, research \& treatment. Hove, UK: Brunner-Routledge, pp. 219255.

13. Pinto-Gouveia J, Ferreira C, Duarte C (2014) Thinness in the pursuit for social safeness: an integrative model of social rank mentality to explain eating psychopathology. Clinical psychology and psychotherapy 21(2): 154 - 165. doi: 10.1002/cpp.1820

14. Troop NA, Allan S, Treasure JL, Katzman M (2003) Social comparison and submissive behaviour in eating disorders. Psychology and Psychotherapy: Theory, Research and Practice 76: 237-249. doi:10.1348/147608303322362479

15. Ferreira C, Pinto-Gouveia J, Duarte C (2013) Drive for thinness as a women's strategy to avoid inferiority. Internacional Journal of Psychology and Psychological Therapy 13(1): 15-29. 
16. Cockell SJ, Hewitt PL, Seal B, Sherry S, Goldner EM, Flett GL, Remick RA (2002) Trait and self-presentational dimensions of perfectionism among women with anorexia nervosa. Cogn Ther Res 26(6):745-758. doi:10.1023/A:102123741636

17. Strahan EJ, Wilson AE, Cressman KE, Buote VM (2006) Comparing to perfection: how cultural norms for appearance affect social comparisons and self-image. Body Image 3:211-227. doi:10.1016/j.bodyim.2006.07.004

18. Hayes SC, Strosahl K, Wilson KG (1999) Acceptance and commitment therapy: An experiential approach to behavior change. New York, Guilford Press.

19. Hayes SC, Strosahl K, Wilson KG (2012) Acceptance and commitment therapy: The process and practice of mindful change (2nd ed.). London, Routledge.

20. Hayes SC, Luoma JB, Bond F, Masuda A, Lillis J (2006) Acceptance and commitment therapy: Model, processes and outcomes. Behaviour Research and Therapy 44: 1-25. doi: 10.1016/j.brat.2005.06.006.

21. Hayes SC, Gifford EV (1997) The trouble with language: Experiential avoidance, rules and the nature of verbal events. Psychological Science 8: 170-173.

22. Campbell-Sills L, Barlow DH, Brown TA, Hofmann SG (2006) Effects of suppression and acceptance on emotional responses on individuals with anxiety and mood disorders. Behavior Research and Therapy 23: 1037-1046.

23. Nolen-Hoeksema S, Harrel ZA (2002) Rumination, Depression, and Alcohol Use: Tests of Gender Differences. Journal of Cognitive Psychotherapy: An International Quarterly 16: 391-403.

24. Santanello AW, Gardner FL (2007) The role of experiential avoidance in the relationship between maladaptive perfectionism and worry. Cognitive Therapy and Research 31: 319-332. doi: 10.1007/s10608-006-9000-6. 
25. Kashdan TB, Barrios V, Forsyth JP, Steger MF (2006) Experiential avoidance as a generalized psychological vulnerability: Comparisons with coping and emotion regulation strategies. Behaviour Research and Therapy 9: 1301-1320.

26. Heffner M, Eifert GH (2004) The Anorexia Workbook: How to Accept Yourself, Heal Your Suffering, and Reclaim Your Life. New Harbinger Publications.

27. Claes L, Vandereycken W, Vertommen H (2001) Self-injurious behaviours in eatingdisordered patients. Eating Behaviours 2: 263-272.

28. Fairburn CG, Cooper Z, Shafran R (2003) Cognitive-behaviour therapy for eating disorders: A "transdiagnostic" theory and treatment. Behaviour Research and Therapy 41: 509-528.

29. Sauer S, Baer RA (2010) Mindfulness and decentering as mechanisms of change in mindfulness and acceptance-based interventions. In: Baer RA (ed) Assessing mindfulness and acceptance processes in clients: Illuminating the theory and practice of change. New Harbinger, pp. 25-50

30. Fresco DM, Moore MT, Dulmen MH, Segal ZV, Ma SH, Teasdale JD, et al (2007) Initial psychometric properties of the Experiences Questionnaire: Validation of a selfreport measure of decentering. Behavior Therapy 38: 234-246.

31. Safran JD, Segal ZV (1990) Interpersonal Process in Cognitive Therapy. New York, Basic Books.

32. Fresco DM, Segal ZV, Buis T, Kennedy S (2007) Relationship of Posttreatment Decentering and Cognitive Reactivity to Relapse in Major Depression. Journal of Consulting and Clinical Psychology 75(3): 447-455. doi: 10.1037/0022006X.75.3.447 
33. Lara P, Trindade IA, Ferreira C (2014) Can the impact of body dissatisfaction on disordered eating be weakened by one's decentering abilities? Eating Behaviors 5(3): 392-396. doi:10.1016/j.eatbeh.2014.04.012

34. WHO (1995) Physical status: the use and interpretation of anthropometry. Reports of a WHO Expert Committee. WHO Technical Report series 854. Geneva, World Health Organization.

35. Poínhos R, Franchini B, Afonso C, Correia F, Teixeira VH, Moreira P, Durão C, Pinho O, Silva D, Lima Reis JP, Veríssimo T, de Almeida MDV (2009) Alimentação e estilos de vida da população Portuguesa: metodologia e resultados preliminares [Alimentation and life styles of the Portuguese population: methodology and preliminary results]. Alimentação Humana 15(3): 43-60.

36. Thompson, J.K., \& Altabe, M.N. (1991), Psychometric qualities of the figure rating scale. International Journal of Eating Disorders, 10(5), 615-619. doi:10.1002/1098108X(199109)10:5<615::AID-EAT2260100514>3.0.CO;2-K

37. Ferreira C (2003) Anorexia Nervosa: A expressão visível do invisível. Contributos para a avaliação de atitudes e comportamentos em relação ao peso e à imagem corporal [Anorexia Nervosa: The visible expression of the invisible. Contributions for the assessment of attitudes and behaviors in relation to weight and body image]. (Unpublished master's thesis). University of Coimbra, Coimbra.

38. Matos M, Pinto-Gouveia J, Gilbert P, Duarte C, Figueiredo C (2015) The Other As Shamer Scale - 2: Development and validation of a short version of a measure of external shame. Personality and Individual Differences 74: 6-11.

39. Goss K, Gilbert P, Allan S (1994) An exploration of shame measures: I: The 'other as shamer'scale. Personality and Individual Differences 17(5): 713-717. doi: $10.1016 / 0191-8869(94) 90149-X$ 
40. Pinto-Gouveia J, Gregório S, Duarte C, Simões L (2012) Decentering: Psychometric properties of the Portuguese version of the experiences questionnaire (EQ). In: Quevedo-Blasco R, Quevedo-Blasco V (eds) Avances en psicología clínica, pp. 445449. Santander: Asociación Española de Psicología Conductual (AEPC). URL: http://www.ispcs.es/xcongreso/portugues/livroresumos.html.

41. Bond FW, Hayes SC, Baer RA, Carpenter KC, Guenole N, Orcutt HK, Waltz T, Zettle RD (2011). Preliminary psychometric properties of the Acceptance and Action Questionnaire-II: A revised measure of psychological flexibility and acceptance. Behavior Therapy 42: 676-688.

42. Pinto-Gouveia J, Gregório S, Dinis A, Xavier A (2012) Experiential Avoidance in clinical and non-clinical samples. International Journal of Psychology and Psychological Therapy 12: 139-156

43. Fairburn CG, Beglin SJ (1994) Assessment of eating disorders: Interview of selfreport questionnaire? International Journal of Eating Disorders 16(4): 363-370. doi: 10.1002/1098-108X(199412).

44. Machado PP, Martins C, Vaz AR, Conceição E, Bastos AP, Gonçalves S (2014) Eating disorder Examination questionnaire: psychometric properties and norms for the Portuguese population. European Eating Disorders Review 22(6): 448-453. doi:10.1002/erv.2318.

45. Fairburn CG, Cooper Z (1993) The eating disorder examination. In: Fairburn CG, Wilson GT (Eds.), Binge eating: Nature, assessment, and treatment (12th ed.). New York, Guilford, pp. 317-360.

46. Arbuckle JL (2006) Amos (Version 7.0) [Computer Program]. Chicago: SPSS. 
47. Cohen J, Cohen P, West S G, Aiken LS (2003) Applied multiple regression/correlation analysis for the behavioral sciences (3rd ed.). Hillsdale, Erlbaum.

48. Hu L, Bentler P (1999) Cutoff Criteria for Fit Indexes in Covariance Structure Analysis: Conventional Criteria Versus New Alternatives. Structural Equation Modeling 6(1): 1-55.

49. Hair J, Anderson R, Tatham R, Black W (1998) Multivariate Data Analysis (5th ed.). London, Prentice Hall International.

50. Hopper D, Coughlan J, Mullen M (2008). Structural Equation Modelling: Guidelines for Determining Model Fit. Electronic Journal of Business Research Methods 6(1): $53-60$

51. Byrne BM (2010) Structural equation modeling with AMOS: Basic concepts, applications, and programming (2nd ed.). Mahwah, NJ: Erlbaum.

52. Kline RB (2005) Principles and Practice of Structural Equation Modeling (2nd ed.). New York, Guilford Press.

53. Field A (2004) Discovering statistics using SPSS (3th ed.). London, Sage Publications. 